\title{
Have malignancy rates increased in thyroidectomy cases?
}

Burhan Hakan Kanat ${ }^{1}$, Ferhat Çay ${ }^{2}$, Nizamettin Kutluer ${ }^{3}$, Nurullah Aksoy ${ }^{4}$, Mehmet Buğra Bozan ${ }^{5}$, Özgen Arslan Solmaz ${ }^{3}$, Zuhal Karaca Karagöz ${ }^{3}$, Sinan İrtegün³, Yusuf Aydın

\author{
'Department of General Surgery, Malatya Turgut Özal University, School of Medicine, \\ Turkey \\ 2Department of General Surgery, Balıkesir University,School of Medicine, Turkey \\ ${ }^{3}$ Department of General Surgery, Fethi Sekin City Hospital, Turkey \\ ${ }^{4}$ Department of General Surgery, Nizip State Hospital, Turkey \\ ${ }^{5}$ Department of General Surgery, Kahramanmaraş Sütçü Imam University School \\ of Medicine, Turkey \\ ${ }^{6}$ Department of Internal Medicine, Malatya Training and Research Hospital, Turkey
}

Submitted: 7 February 2021

Accepted: 27 March 2021

Arch Med Sci Civil Dis 2021; 6: e46-e49

DOI: https://doi.org/10.5114/amscd.2021.105525

Copyright @ 2021 Termedia \& Banach

\section{Abstract}

Introduction: This study aims to review thyroidectomy cases performed by a single surgeon in a single centre during the course of 1 year, to determine if the malignancy rate increased, and to compare the results with the literature.

Material and methods: We retrospectively evaluated data of patients who underwent thyroidectomy between August 2018 and August 2019 in the General Surgery Clinic of our hospital. The malignancy rate was calculated and analysed according to the demographic data of the patients (gender and age), preoperative thyroid nodule sizes, and postoperative pathological mass sizes. Also, age, preoperative nodule size, and tumour size were all evaluated according to gender.

Results: There were a total of 60 patients (14 (23\%) male and $46(77 \%) \mathrm{fe}$ male). The pathology result revealed 16 (26.7\%) malignant and 44 (73.3\%) benign biopsies. The mean age was $46.72 \pm 12.08$ years (20-74). We found that age, preoperative nodule size $(\mathrm{cm})$, pathological tumour size $(\mathrm{cm})$, and thyroid function tests were not significantly associated with malignancy. However, when age, preoperative nodule size, and tumour sizes were evaluated according to gender, it was found that tumour sizes were significantly larger in men than in women $(p<0.001)$. In addition, the mean age of male patients was higher than that of women $(p=0.025)$.

Conclusions: The malignancy rate has increased in the thyroidectomies performed in our centre. This finding is consistent with relevant studies from the last 30 years. Therefore, it is likely that clinicians will continue to handle an increased number of thyroid malignancies.

Key words: thyroidectomy, cancer incidence, treatment.

\section{Introduction}

Currently, the most commonly performed endocrine surgery is thyroidectomy, particularly in regions with iodine deficiency, such as Turkey [1]. These operations have garnered the attention of researchers due to the severity of associated complications, but they are known to yield

\author{
Corresponding author: \\ Burhan Hakan Kanat \\ Department of General \\ Surgery \\ Malatya Turgut \\ Özal University \\ School of Medicine, Turkey \\ E-mail: burhankanat@ \\ hotmail.com
}


fewer complications when performed by experienced surgeons. The method first described by Theodor Kocher in 1880 forms the basis of all thyroid surgeries that have been and are currently being performed [2]. Novel transoral approaches have recently been defined for thyroidectomy; however, the classical Kocher method is still the most commonly used [3].

An increased incidence of malignancy has been described in thyroidectomy materials in the last 30 years. There have also been improvements in intraoperative neuromonitoring techniques and equipment, which help reduce nerve damage complications in thyroid surgery [4-6]. The developing technology makes ultrasonography and biopsy examinations more accessible. As reported in several studies, the malignancy rate in thyroidectomies has been increasing even in operations that are planned for benign causes [1, 7].

This study aims to review thyroidectomy cases performed by a single surgeon in a single centre during the course of 1 year, to determine if the malignancy rate has increased, and to compare the results with the literature.

\section{Material and methods}

The research was conducted following the principles of "World Medical Association Declaration of Helsinki: Ethical Principles for Medical Research Involving Human Subjects". Ethics committee approval was not received for this study because of its retrospective design, but the necessary permissions were obtained from the hospital management.

We retrospectively evaluated data of patients who had undergone thyroidectomy between August 2018 and August 2019 in the General Surgery Clinic of our hospital. After obtaining the required permissions from the hospital management, the data from 72 thyroidectomy patients were retrospectively evaluated. Patient data were accessed via digital records and patient files. Twelve patients with missing or inaccessible data were excluded from the study. A total of 60 patients were included in the study.

The malignancy rate was calculated and analysed according to the demographic data of the patients (gender and age), preoperative thyroid nodule sizes, and postoperative pathological mass sizes. Also, age, preoperative nodule size, and tumour size were all evaluated by gender.

\section{Statistical analysis}

Data were analysed using SPSS version 20. The numerical data were analysed with Student's $t$-test and Mann-Whitney $U$-test, and the categorical data were analysed using the $\chi^{2}$ test. The numerical data were expressed as median (minimum-maximum), and the categorical data were presented as numbers and percentages (\%). A $p$-value $<0.05$ was considered statistically significant.

\section{Results}

There were a total of 60 subjects (14 (23\%) male and 46 (77\%) female). The pathology result revealed that $16(\% 26.7)$ patients had malignancy and $44(73.3 \%)$ had benign biopsies. The mean age was $46.72 \pm 12.08$ years (20-74).

The distribution of the subjects' demographic data (gender and age), preoperative tumour size, postoperative pathological tumour sizes, and thyroid function test results (T3, T4, and TSH) according to malignancy are presented in Table I. Preoperative tumour sizes, postoperative pathological

Table I. Malignancy results according to demographic data (gender and age), preoperative thyroid nodule sizes, and postoperative pathological mass sizes

\begin{tabular}{|lcccc|}
\hline \multirow{2}{*}{ Parameter } & \multicolumn{2}{c}{ Malignancy } & Total & P-value \\
\cline { 2 - 3 } & Positive & Negative & \\
\hline Gender, $n(\%):$ & & $14(18)$ & 0.448 \\
\hline Male & $3(5)$ & $33(55)$ & $46(77)$ & \\
\hline Female & $13(22)$ & $46.84 \pm 12.44(20-74)$ & 0.893 \\
\hline Age [years] & $46.38 \pm 11.43(24-64)$ & $3.81 \pm 1.7(0.45-8.2)$ & 0.561 \\
\hline Preoperative size $[\mathrm{cm}]$ & $3.39 \pm 2.52(0.35-7.7)$ & $2.82 \pm 1.45(0.4-6)$ & 0.77 \\
\hline Tumour size $[\mathrm{cm}]$ & $2.66 \pm 1.92(0.1-6.5)$ & $4.56 \pm 7.48(0.01-45.05)$ & 0.946 \\
\hline TSH & $12.71 \pm 38.73(0.02-157.52)$ & 0.341 \\
\hline T3 & $3.18 \pm 0.68(1.39-4.68)$ & $3.56 \pm 1.65(0.98-13.53)$ & 0.091 \\
\hline T4 & $0.83 \pm 0.2(0.51-1.28)$ & $3.16 \pm 14.63(0.45-98)$ & \\
\hline
\end{tabular}


Burhan Hakan Kanat, Ferhat Çay, Nizamettin Kutluer, Nurullah Aksoy, Mehmet Buğra Bozan, Özgen Arslan Solmaz, Zuhal Karaca Karagöz, Sinan İrtegün, Yusuf Aydın

Table II. Age, preoperative nodule size, and tumour size findings according to gender

\begin{tabular}{|lccc|}
\hline Parameter & \multicolumn{1}{c|}{ Male } & Female & $P$-value \\
\hline Age [years] & $53.21 \pm 11.46(25-74)$ & $44.74 \pm 11.68(20-64)$ & $0.025^{*}$ \\
\hline Preoperative size $[\mathrm{cm}]$ & $3.73 \pm 2.15(0.45-7.3)$ & $3.68 \pm 1.91(0.35-8.2)$ & 0.94 \\
\hline Tumour size $[\mathrm{cm}]$ & $4.28 \pm 1.46(1.5-6.5)$ & $2.32 \pm 1.31(0.1-5.7)$ & $<0.001^{*}$ \\
\hline TSH & $5.66 \pm 4.99(0.01-14.96)$ & $7.12 \pm 23.92(0.02-157.52)$ & 0.105 \\
\hline T3 & $3.8 \pm 2.9(0.98-13.53)$ & $3.36 \pm 0.56(1.39-4.71)$ & 0.392 \\
\hline T4 & $0.88 \pm 0.24(0.63-1.48)$ & $3.09 \pm 14.07(0.45-98)$ & 0.331 \\
\hline
\end{tabular}

tumour sizes, and thyroid function test results ( $T 3$, T4, and TSH) according to gender are presented in Table II.

We found that age, preoperative nodule size $(\mathrm{cm})$, pathological tumour size $(\mathrm{cm})$, and thyroid function tests were not significantly associated with malignancy. However, when age, preoperative nodule size, and tumour sizes were evaluated according to gender, it was found that tumour sizes were significantly larger in men than in women $(p<0.001)$. In addition, the mean age of male patients was higher than that of women $(p=0.025)$.

\section{Discussion}

Thyroidectomies are the most common type of endocrine surgery performed in general surgery clinics. In particular, surgeons from endemic regions such as Turkey have more experience in these surgeries. Increased access to healthcare and doctors and rapid technological development mean that these patients can be offered more assessment possibilities such as ultrasonography and fine-needle aspiration biopsy.

Thyroid cancers are generally more common in women than in men, and the mean age of initial diagnosis is younger in women $[8,9]$. In this regard, our results are consistent with the literature. In addition, studies report that the mean size of the tumour is significantly larger in men than in women. We also obtained similar results.

One of the most frequently used guidelines in approaching thyroid patients is the American Thyroid Association (ATA) guideline. One of the most important roles of the ATA guideline is to prevent non-indicated surgeries. An increase in thyroid cancers has been reported for both genders since the late 1980s. This increase may be associated with certain temporary changes such as obesity, genetic susceptibility, environmental factors, and iodine replacement efforts in regions with endemic iodine deficiency [8-14]. However, this increase can also be attributed to developing diagnostic methods, increased awareness, the wide and effective use of neck ultrasonography, and the in- creased ability to detect slow-growing neck masses $[15,16]$.

Researchers have been divided into two regarding the reason for the recent increase in thyroid cancer cases around the world. Several authors suggest that this is a result of increased diagnostic capabilities $[17,18]$. Other authors argue that this is a true increase that results from environmental and lifestyle changes [19-22].

This study aims to determine whether there is an increased malignancy rate in the thyroidectomies performed during the course of 1 year as compared to the available literature. In their series of 671 cases, Dagli and Artas reported the malignancy rate to be $21.6 \%$ [5]. In our study, we found this rate to be $26.7 \%$. The number of patients included in this study is approximately half of the annual number of patients included in the Dagli and Altas study; however, it can still be inferred that the malignancy rate has increased in thyroidectomy cases [23].

In the United States, it has been reported that the rate of thyroid cancer was $2.4 \%$ between 1980 and 1997, and it increased to 6.6\% between 1997 and 2009 [24]. Erbil et al. conducted a similar study while excluding patients with preoperative or perioperative suspected malignancy and reported that the histopathological malignancy rate was $11 \%$ in the remaining subjects. This rate concerns patients operated for non-toxic multinodular goitre [1]. We based our study on pathology results regardless of surgical indications.

Both our results and the literature indicates that the incidence of thyroid cancer has increased, which has translated into an increased malignancy rate in thyroidectomy materials. One of the most significant reasons behind this result is in dicated to be the increased accessibility to medical technology [25]. Both current and previous studies report and increasing thyroid cancer prevalence [26].

In conclusion, the malignancy rate has increased in the thyroidectomies performed in our centre. This finding is consistent with relevant studies from the last 30 years. Therefore, it is 
likely that clinicians will continue to handle an increased number of thyroid malignancies. However, further studies with larger samples are needed to support our results.

\section{Conflict of interest}

The authors declare no conflict of interest.

\section{References}

1. Erbil Y, Barbaros U, Salmaslioglu A, Yanik BT, Bozbora A, Ozarmagan S. The advantage of near-total thyroidectomy to avoid postoperative hypoparathyroidism in benign multinodular goiter. Langenbecks Arch Surg 2006; 391: 567-73.

2. Uludağ $M$, İşgör A. Scarless thyroidectomy: transoral endoscopic thyroidectomy by vestibular approach. Med Bull Sisli Etfal Hospital 2017; 51: 169-83.

3. Cottrill EE, Funk EK, Goldenberg D, Goyal N. Transoral thyroidectomy using a flexible robotic system: a preclinical cadaver feasibility study. Laryngoscope 2019; 129 . 1482-7.

4. Gardner IH, Doherty GM, McAneny D. Intraoperative nerve monitoring during thyroid surgery. Curr Opin Endocrinol Diabetes Obes 2016; 23: 394-9.

5. Dağlı AF, Artaş G. The prevalence of thyroid cancer and sub-types in Elazığ: a five year experience. İönü Üniversitesi Sağıık Hizmetleri Meslek Yüksekokulu Dergisi 2016; 4: 1-5.

6. Sahin N, Üçer Ö. The incidence of thyroid cancer at thyroidectomy materials in Malatya. Dicle Med J 2013; 40: 570-3.

7. Maturo A, Tromba L, De Anna L, et al. Incidental thyroid carcinomas. A retrospective study. G Chir 2017; 38: 94-101.

8. Charles BF, et al. Schwartz's principels of surgery. In: Thyroid, Parathyroid, Adrenal. Lal G, Clark HO (eds.). McGraw Hill Company, New York 2010: 1343-408.

9. Townsend MC, et al. Sabiston Textbook of Surgery. In: Thyroid. Hanks BJ (ed.). Saunders Elsevier, Philadelphia 2004: 947-99.

10. Kitahara CM, McCullough ML, Franceschi S, et al. Anthropometric factors and thyroid cancer risk by histological subtype: pooled analysis of 22 prospective studies. Thyroid 2016; 26: 306-18.

11. Kitahara C, Gamborg M, Berrington A, Sørensen T, Baker J. Childhood height and body mass index were associated with risk of adult thyroid cancer in a large cohort study. Cancer Res 2014; 74: 235-42.

12. Kitahara CM, Linet MS, Beane Freeman LE, et al. Cigarette smoking, alcohol intake, and thyroid cancer risk: a pooled analysis of five prospective studies in the United States. Cancer Causes Control 2012; 23: 1615-24.

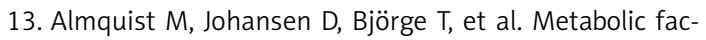
tors and risk of thyroid cancer in the Metabolic Syndrome and Cancer Project (Me-Can). Cancer Causes Control 2011; 22: 743-51.

14. Wiersinga W. Smoking and thyroid. Clin Endocrinol 2013; 79: 145-51.

15. Burgess J. Temporal trends for thyroid carcinoma in Australia: an increasing incidence of papillary thyroid carcinoma (1982-1997). Thyroid 2002; 12: 141-9.

16. Colonna M, Grosclaude P, Remontet L, et al. Incidence of thyroid cancer in adults recorded by French cancer registries (1978-1997). Eur J Cancer 2002; 38: 1762-8.
17. Davies L, Welch HG. Increasing incidence of thyroid cancer in the United States, 1973-2002. JAMA 2006; 295: 2164-7.

18. Grodski S, Brown T, Sidhu S, et al. Increasing incidence of thyroid cancer is due to increased pathologic detection. Surgery 2008; 144: 1038-43.

19. Enewold L, Zhu K, Ron E, et al. Rising thyroid cancer incidence in the United States by demographic and tumor characteristics, 1980-2005. Cancer Epidemiol Biomarkers Prev 2009; 18: 784-91.

20. Rego-Iraeta A, Pérez-Méndez LF, Mantinan B, GarciaMayor RV. Time trends for thyroid cancer in northwestern Spain: true rise in the incidence of micro and larger forms of papillary thyroid carcinoma. Thyroid 2009; 19 : 333-40.

21. Simard EP, Ward EM, Siegel R, Jemal A. Cancers with increasing incidence trends in the United States: 1999 through 2008. CA Cancer J Clin 2012; 62: 118-28.

22. Chen AY, Jemal A, Ward EM. Increasing incidence of differentiated thyroid cancer in the United States, 19882005. Cancer 2009; 115: 3801-7.

23. Aschebrook-Kilfoy B, Ward MH, Sabra MM, Devesa SS. Thyroid cancer incidence patterns in the United States by histologic type, 1992-2006. Thyroid 2011; 21: 125-34.

24. Pellegriti G, Frasca F, Regalbuto C, Squatrito S, Vigneri R. Worldwide increasing rate of thyroid cancer: update on epidemiology and risk factors. J Cancer Epidemiol 2013; 2013: 965212.

25. Kitahara CM, Sosa JA. The changing incidence of thyroid cancer. Nat Rev Endocrinol 2016; 12: 646-53.

26. Burgess JR. Temporal trends for thyroid carcinoma in Australia: an increasing incidence of papillary thyroid carcinoma (1982-1997). Thyroid 2002; 12: 141-9. 